\title{
High environmental stress and productivity increase functional diversity along a deep-sea hydrothermal vent gradient
}

\author{
J. M. Alfaro-Lucas iD ${ }^{1,4}$ F. Pradillon iD,${ }^{1}$ D. Zeppilli iD,${ }^{1}$ L. N. Michel iD ${ }^{1}$ P. Martinez-Arbizu iD, ${ }^{2}$ \\ H. Tanaka iD ${ }^{3}$ M. Foviaux, ${ }^{1}$ and J. Sarrazin ${ }^{1}$ \\ ${ }^{1}$ Ifremer, EEP, Plouzané, France \\ ${ }^{2}$ Senckenberg am Meer, German Center for Marine Biodiversity Research, Wilhelmshaven, Germany \\ ${ }^{3}$ Tokyo Sea Life Park, Tokyo, Japan
}

Citation: Alfaro-Lucas, J. M., F. Pradillon, D. Zeppilli, L. N. Michel, P. Martinez-Arbizu, H. Tanaka, M. Foviaux, and J. Sarrazin. 2020. High environmental stress and productivity increase functional diversity along a deep-sea hydrothermal vent gradient. Ecology 101(11):e03144. 10.1002/ecy.3144

Abstract. Productivity and environmental stress are major drivers of multiple biodiversity facets and faunal community structure. Little is known on their interacting effects on early community assembly processes in the deep sea $(>200 \mathrm{~m})$, the largest environment on Earth. However, at hydrothermal vents productivity correlates, at least partially, with environmental stress. Here, we studied the colonization of rock substrata deployed along a deep-sea hydrothermal vent gradient at four sites with and without direct influence of vent fluids at 1,700-m depth in the Lucky Strike vent field (Mid-Atlantic Ridge [MAR]). We examined in detail the composition of faunal communities $(>20 \mu \mathrm{m})$ established after $2 \mathrm{yr}$ and evaluated species and functional patterns. We expected the stressful hydrothermal activity to (1) limit functional diversity and (2) filter for traits clustering functionally similar species. However, our observations did not support our hypotheses. On the contrary, our results show that hydrothermal activity enhanced functional diversity. Moreover, despite high species diversity, environmental conditions at surrounding sites appear to filter for specific traits, thereby reducing functional richness. In fact, diversity in ecological functions may relax the effect of competition, allowing several species to coexist in high densities in the reduced space of the highly productive vent habitats under direct fluid emissions. We suggest that the high productivity at fluid-influenced sites supports higher functional diversity and traits that are more energetically expensive. The presence of exclusive species and functional entities led to a high turnover between surrounding sites. As a result, some of these sites contributed more than expected to the total species and functional $\beta$ diversities. The observed faunal overlap and energy links (exported productivity) suggest that rather than operating as separate entities, habitats with and without influence of hydrothermal fluids may be considered as interconnected entities. Low functional richness and environmental filtering suggest that surrounding areas, with their very heterogeneous species and functional assemblages, may be especially vulnerable to environmental changes related to natural and anthropogenic impacts, including deep-sea mining.

Key words: colonization; community assembly; energy; environmental filtering; functional $\beta$-diversity; species $\beta$-diversity.

\section{INTRODUCTION}

Productivity and environmental stress are major drivers of biodiversity patterns and community structure (Chase and Leibold 2002, Chase 2010, Weiher et al. 2011). Locally, species richness is often positively correlated with primary productivity (Mittelbach et al. 2001, Chase 2010), whereas the relationship between functional richness and productivity remains more elusive (Lamanna et al. 2014, McClain et al. 2018). High environmental stress "filters" for suitable species traits, therefore limiting colonization and reducing species and

Manuscript received 16 November 2019; revised 18 May 2020; accepted 9 June 2020. Corresponding Editor: Alan L. Shanks.

${ }^{4}$ E-mail: joanmanel.alfaro@e-campus.uab.cat functional diversity (Weiher et al. 2011, Mouillot et al. 2013, Teixidó et al. 2018). Studies on marine shallowwater gradients $(<0.5-3-\mathrm{m}$ depth) have shown that stress has negative effects on colonization, species, and functional richness, and assemblage structural and trophic complexities (Hall-Spencer et al. 2008, Fabricius et al. 2014, Vizzini et al. 2017, Teixidó et al. 2018). Concomitant increase in productivity may in some cases attenuate some stress effects through higher food supply (Kroeker et al. 2011, Garrard et al. 2014) but evidence does not suggest so for the functional facet (Teixidó et al. 2018). Despite their importance, interactive effects of these drivers on the structure of communities in the deep sea $(>200 \mathrm{~m})$, the largest environment on Earth, remain poorly understood (McClain and Rex 2015, McClain and Schlacher 2015, Ashford et al. 2018). 
The diverse communities in the relatively homogeneous and stable deep sea (Snelgrove and Smith 2002) largely depend on the supply of organic matter produced in shallower photosynthetically active waters (Ruhl and Smith 2004, Ruhl et al. 2008). In this context, deep-sea hydrothermal vents (HV) may be used as natural laboratories because they are hot spots of chemoautolithotrophic-based primary productivity and biomass where productivity correlates, at least partially, with environmental stress (Johnson et al. 1988, 1994, reviewed in Le Bris et al. 2019). At HVs, oxygenated cold seawater percolates through and reacts with the ocean crust, forming oxygen-depleted, acidic, and toxic vent fluids (reviewed in Le Bris et al. 2019). Their dilution with oxygenated water creates environments hosting microbial communities that obtain their energy through the oxidation of chemical compounds, which makes up the trophic basis of dense faunal assemblages (Sievert and Vetriani 2012). HV assemblages are often dominated by large invertebrates hosting chemosymbiotic microbial communities considered major primary producers. These holobionts (entities formed by invertebrate hosts and their symbiotic partners; sensu Le Bris et al. 2019) inhabit distinct niches along environmental gradients, forming mosaic-like patterns and acting as foundation/ engineer species (Sarrazin et al. 1997, Shank et al. 1998, Luther et al. 2001, Govenar 2010).

Smaller invertebrates are associated with these foundation species forming dense low-diversity assemblages compared those of the surrounding deep sea (Govenar et al. 2005, Gollner et al. 2010, Zeppilli et al. 2015, Plum et al. 2017). The majority of vent taxa exhibits behavioral and/or physiological adaptations to deal with environmental stress, explaining the low species diversity of hydrothermal ecosystems (Bates et al. 2010, Govenar 2010, Gollner et al. 2015a, $b$, Zeppilli et al. 2018). The stress/productivity gradients strongly structure faunal communities, although very little is known about the biodiversity and drivers of community structure of more stable, less productive areas with no direct fluid influence (Luther et al. 2001, Micheli et al. 2002, Mullineaux et al. 2003, Bates et al. 2010, Gollner et al. 2015b). Locally, species and trophic diversities are typically low in areas of higher fluid flux, higher in areas of lower emissions, and even higher in more stable yet less productive adjacent environments without direct influence of vent fluid emissions (Govenar et al. 2005, Gollner et al. 2010, 2015b, Sarrazin et al. 2015, Zeppilli et al. 2015, Sen et al. 2016, Bell et al. 2017, Plum et al. 2017). To date, however, local functional diversity patterns remain largely unexplored in these ecosystems (but see Chapman et al. 2018, 2019). Coupling taxonomic and functional-traitbased approaches can provide crucial insights into processes structuring faunal communities and their responses to global environmental changes and industrial impacts (McGill et al. 2006).

The objective of the present study was to examine the effect of different productivity/stress regimes produced by the influence of vent fluid emissions on the early faunal community assembly including meio- and macrofauna on a series of rock substratum blocks that were deployed for $2 \mathrm{yr}$ at four contrasting deep-sea sites, that is, with and without vent fluid emissions. We examined and compared the species and functional $\alpha$ - and $\beta$-diversities and community structure, and evaluated the use of chemosynthetic productivity by the colonizing fauna at the different sites. We hypothesized that (H1) functional diversity is lower at sites with direct influence of vent fluids because of environmental constraints on basal nutritional sources (Bell et al. 2017) and species physiology (Luther et al. 2001, Bates et al. 2010), and (H2) environment filters and clusters functionally similar species in sites with direct influence of vent emissions, reducing colonization to well-adapted species owning traits that are resilient to stress (Teixidó et al. 2018).

\section{Materials ANd Methods}

\section{Study area, experimental setup, and sample processing}

We deployed size-standardized slate blocks $\left(10 \mathrm{~cm}^{3}\right)$ for $2 \mathrm{yr}$ at four different "sites" characterized by a decreasing level of hydrothermal activity, hereafter referred to as the "active," "intermediate," "periphery," and "far" sites along and nearby the hydrothermally active Eiffel Tower (ET) edifice (Lucky Strike vent field, 1,700-m depth, Mid-Atlantic Ridge; Table 1 and Fig. 1). Based on previous pilot studies, slate blocks were chosen for their basalt-like, smooth, and inert surface (Cuvelier et al. 2014, Zeppilli et al. 2015, Plum et al. 2017). Located on the northwest side of the ET, the active site shows the most vigorous activity, with the presence of microbial mats and a high-temperature chimney within the vicinity (few centimeters) of the deployed substrata. The intermediate site is located further down on the western side of the edifice, in an area of visible diffuse flow. The active and intermediate sites are colonized by dense assemblages of the foundation species Bathymodiolus azoricus. The periphery site is a poorly sedimented area with no visible hydrothermal activity located between the ET ( $\sim 50 \mathrm{~m})$ and Montségur edifices $(\sim 85 \mathrm{~m})$. Finally, the far site is situated on a basaltic seabed with no visible hydrothermal activity on the west side of the Lucky Strike lava lake, at $~ 90, \sim 120$, and $\sim 470 \mathrm{~m}$ away from the Helen, Pico and ET active edifices, respectively (Table 1 and Fig. 1).

Slate blocks were deployed during the MoMARSAT $2013^{5}$ cruise on board the R/V Pourquoi pas?, using the ROV Victor6000. Three blocks were deployed at each of the four sites. Temperature was recorded for 9 months every 15 min using autonomous NKE ST 6000 temperature probe attached to wood blocks from a parallel experiment running at each site (Table 1). The physicochemical environment, characterized by temperature,

\footnotetext{
${ }^{5}$ https://doi.org/10.17600/13030040
} 
TABLE 1. Distance of the substrata in relation to nearest active vent sites and temperature values registered at the four study sites.

\begin{tabular}{lccccccc}
\hline \hline Site & $\begin{array}{c}\text { Closest active } \\
\text { vent }(\mathrm{m})\end{array}$ & $\begin{array}{c}\text { Mean } \pm \mathrm{SD} \text { tem- } \\
\text { perature }\end{array}$ & $\begin{array}{c}\text { Minimum tem- } \\
\text { perature }\end{array}$ & $\begin{array}{c}\text { Maximum tem- } \\
\text { perature }\end{array}$ & $\begin{array}{c}\text { Temperature } \\
\text { range }\end{array}$ & $\begin{array}{c}\text { HVF } \\
(\%)\end{array}$ & \begin{tabular}{c}
$\mathrm{pH}$ \\
\hline Active
\end{tabular} \\
Intermediate & 0 & $7.93 \pm 2.13$ & 4.69 & 21.6 & 16.91 & 1.11 & 6.15 \\
Periphery & 0 & $5.79 \pm 0.77$ & 4.53 & 12.2 & 7.67 & 0.44 & 6.7 \\
Far & $\sim 50$ & $4.62 \pm 0.07$ & 4.38 & 4.87 & 0.49 & 0.07 & 7.27 \\
& $\sim 90$ & $4.55 \pm 0.07$ & 4.32 & 4.77 & 0.44 & 0.05 & 7.31 \\
\hline
\end{tabular}

Notes: Hydrothermal vent fluid input (HVF) and $\mathrm{pH}$ were derived from the formulas provided by Sarradin et al. (2009) (see Appendix S1 for details). All temperatures are in degrees Celsius.

hydrothermal vent fluid flux (HVF), and pH showed significant intersite differences, confirming expected contrasts in physical and chemical conditions between our sites (Table 1; see further details in Appendix S1). All substrata were recovered by Victor6000, during the MoMARSAT 2015 cruise, ${ }^{6} 2 \mathrm{yr}$ after their deployment. Upon recovery, each slate block was placed in an individual isotherm sampling box. Once on board, they were carefully washed with filtered seawater and sieved through $300-$ and $20-\mu \mathrm{m}$ meshes. The $20-\mu \mathrm{m}$ samples were preserved in $4 \%$ seawater-buffered formalin and $300-\mu \mathrm{m}$ samples were preserved either in $96 \%$ ethanol (two slate blocks from each site) or in $4 \%$ seawater-buffered formalin (the third slate block of each site) for further examination in the laboratory. Once in the laboratory, sieved samples were sorted manually under a stereo microscope and all taxa were counted and identified to the lowest taxonomic level possible. Larvae and individuals without heads were discarded and not considered further. Because of the high abundance of organisms, the $20-\mu \mathrm{m}$ samples were transferred to $200-\mathrm{ml}$ beakers and three subsamples of $5 \mathrm{ml}$ each were taken from the original volumes and stained with phloxine following Plum et al. (2017). For each subsample, a maximum of 100 randomly collected individuals of each taxonomic group were mounted on slides and identified to the lowest taxonomical level possible. Prior to mounting, nematodes underwent a formalin-ethanol-glycerol treatment to prevent dehydration (see Zeppilli et al. 2015). The average number of species individuals per subsample was extrapolated to the original sample volume to estimate the total abundance of species (Plum et al. 2017) and summed to the $300-\mu \mathrm{m}$ sample abundances.

\section{Taxonomical and functional biodiversity indices}

Bathymodiolus azoricus is the main foundation species of the Lucky Strike vent field and of the ET, forming dense mussel-bed habitats (Desbruyères et al. 2001). Because its inclusion would certainly drive the main trends in biodiversity metrics, we excluded it from our analyses. We evaluated faunal sampling effort with sample-based species accumulation curves. We estimated the taxonomic diversity as the total $\left(\mathrm{S}_{\text {Total }}\right)$ and mean species

${ }^{6} \mathrm{https} / / /$ doi.org/10.17600/15000200 richness $(\mathrm{S})$, mean abundance $(\mathrm{N})$, the mean expected species richness in a 158-individual sample $\left(\mathrm{ES}_{(158)}\right.$, which corresponds to the minimum abundance found in a single rock block), the mean Simpson's inverse index (1-D) and the mean Pielou'sevenness index $\left(\mathrm{J}^{\prime}\right)$ per site.

We analyzed three functional response traits that are related to productivity and stress. They include "adult mobility" (hereafter "mobility"), "maximum adult body size" (hereafter "size"), and "feeding mechanism" (see trait definitions, modalities, references, and data sets in Appendix S2). Traits were obtained from direct measurements and/or literature, including the sFDVent database (Chapman et al. 2019). We estimated the total (FRic $\left.{ }_{\text {Total }}\right)$ and mean functional richness (FRic) per site as the percentage of functional volume at each site derived from a multidimensional functional space (Mouchet et al. 2010). This space was constructed using synthetic components of a principal coordinate analysis (PCoA) encapsulating the variation of functional entities, that is, the unique trait combinations, of fauna at each site. The functional entity coordinates on the first five PCoA axes $(95.5 \%$ of variance) were used to estimate FRic ${ }_{\text {Total }}$ and FRic. We also calculated the total $\left(\mathrm{FE}_{\text {Total }}\right)$ and mean number of functional entities (FE), the mean expected functional entities in a 158-individuals sample $\left(\mathrm{EFE}_{(158)}\right)$, mean Rao's quadratic entropy (RaoQ), used to measure functional diversity (BottaDukát 2005), and the mean functional evenness (FEve) at each site.

Null models were run to test if the influence of stressful vent fluids in active and intermediate sites filtered for certain traits, and therefore contribute to reduce functional richness (FRic) more than expected by chance. Null models were run 4,999 times for each site to generate $95 \%$ confidence intervals of expected FRic values if no forces were constraining assemblages, that is, a random sorting of species, maintaining the observed number of species per site. We compared these confidence intervals with observed FRic values. Observed FRic values do not deviate from null expectations if they fell within confidence intervals. Lower observed FRic than expected by chance typically arise under environmental filtering (Chase 2010, Weiher et al. 2011, Teixidó et al. 2018) because the environment "selects" for well-adapted species and thus "filters" for certain traits reducing FRic more than what it would be expected by chance. 


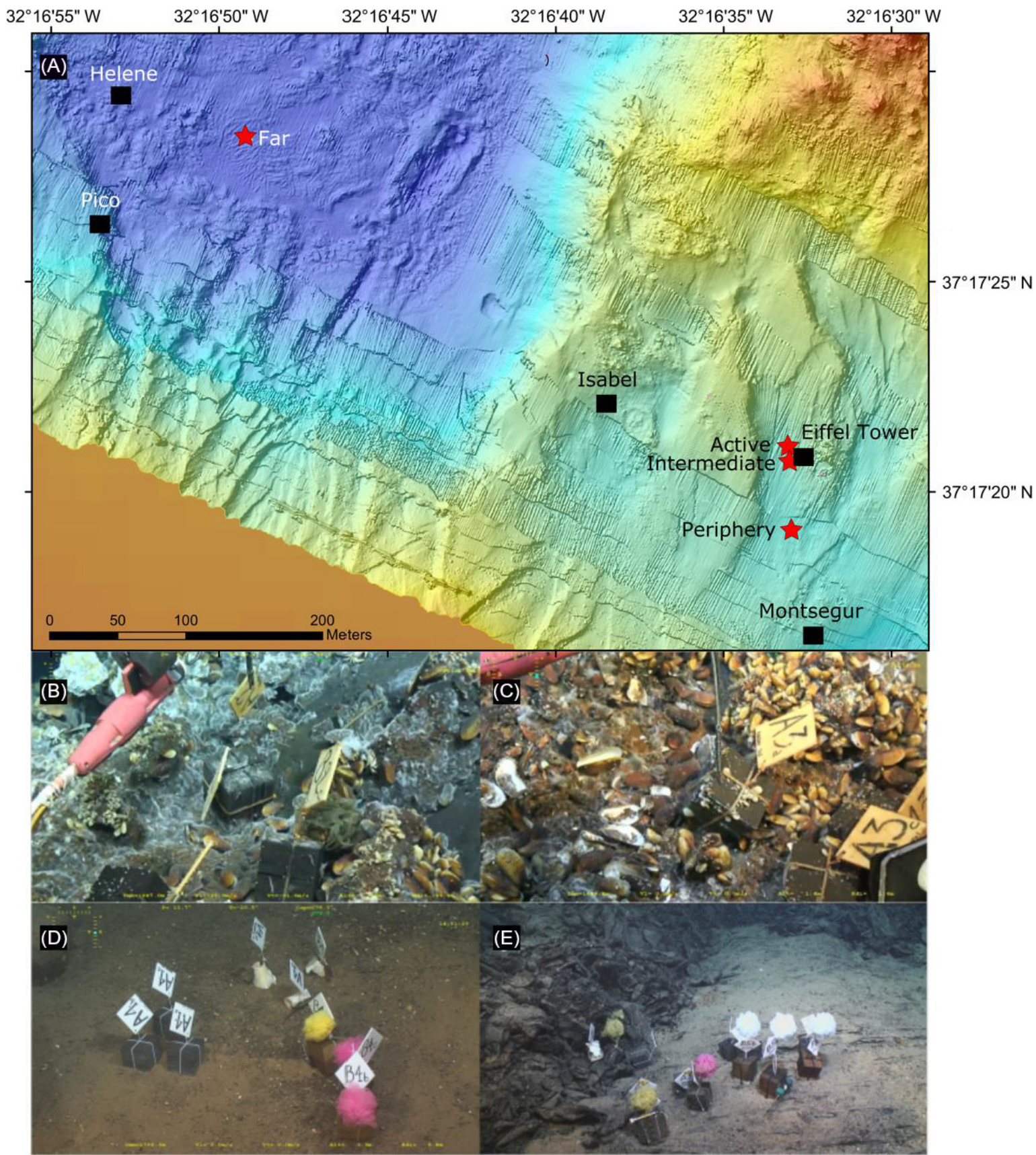

FIG. 1. The southeast region of the Lucky Strike vent field located at 1,700 $\mathrm{m}$ depth on the Mid-Atlantic Ridge, south of the Azores. (A) Locations of the four deployment sites (red stars) and surrounding main active hydrothermal edifices (black squares). Note that the far site is located further west, in the fossil lava lake. Colonized substratum blocks at (B) active, (C) intermediate, (D) periphery, and (E) far sites. Also, visible in the photos are the other types of substratum used in parallel experiments.

To estimate the total taxonomic and functional $\beta$-diversities $\left(\mathrm{sBD}_{\text {Total }}\right.$ and $\left.\mathrm{fBD}_{\text {Total }}\right)$ and the mechanisms driving overall $\beta$-diversity, we estimated the total variance of the presence-absence species-by-site and FEsby-site tables using the Jaccard dissimilarity coefficient (Legendre and De Cáceres 2013, Legendre 2014).
$\mathrm{BD}_{\text {Total }}$ computed from Jaccard dissimilarity coefficient reaches its maximum value (1) when all sites exhibit totally different species compositions (Legendre and De Cáceres 2013). $\mathrm{BD}_{\text {Total }}$ was decomposed into species turnover and nestedness to assess the mechanisms generating $\beta$-diversity (Baselga 2010, Legendre 2014). 
The degree of uniqueness of each site in terms of species and FE composition was estimated by the local contribution to $\beta$-diversity (LCBD) indices (Legendre and De Cáceres 2013). LCBD indices were tested for significance using random permutations assuming the null hypothesis that species and FEs were randomly distributed among sites. Furthermore, to estimate the dissimilarity between each site and the processes driving dissimilarities, $\beta$-diversity between each pair of sites (D) was estimated and decomposed into turnover and nestedness.

\section{Analyses of species and functional community structure}

We ran distance-based redundancy analyses (dbRDA) of Hellinger-transformed species abundances and abundance-weighted FEs constrained by a "site" factor (see Appendix S1 for details) to test if species assemblages and FEs, respectively, were differently structured by the conditions of each site. Additionally, we performed multiple factor analyses (MFAs), that is, symmetric correlative analyses, to visualize and compare the taxonomic and FE structures of assemblages and to characterize species and FE associations with sites. We used the RV coefficient, which measures the relatedness of two data sets derived from separate ordinations (Robert and Escoufier 1976), to assess the correlation of the taxonomic and functional community structure and tested significances using permutations (Josse et al. 2008). The RV coefficient ranges from 0 (no correlation between data sets) to 1 .

\section{Isotope analyses}

The $\delta^{13} \mathrm{C}, \delta^{15} \mathrm{~N}$, and $\delta^{34} \mathrm{~S}$ of 19 taxa were analyzed (see Appendix S3 for details). Results were qualitatively compared to values considered representative of different biogeochemical reactions. They included multiple chemosynthetic pathways such as methane oxidation $\left(\delta^{13} \mathrm{C}\right.$ ranging from $-15 \%$ to $-10 \%$ ), reductive tricarboxylic acid (rTCA) cycle-based sulfide oxidation $\left(\delta^{13} \mathrm{C}=-12.9 \pm 3.4 \%\right.$ ) , and Calvin-Benson-Bassham (CBB) cycle-based sulfide oxidation $\left(\delta^{13} \mathrm{C}\right.$ ranging from $-36 \%$ to $-30 \%$; Portail et al. 2018 and references therein). $\delta^{15} \mathrm{~N}$ can reflect two large inorganic sources with very different isotopic compositions in chemosynthetic environments, that is, nitrates $\left(\delta^{15} \mathrm{~N}=5-7 \%\right.$ ) and ammonium $\left(\delta^{15} \mathrm{~N}<0 \%\right.$; Lee and Childress 1996). In contrast, photosynthetic-derived organic matter shows $\delta^{13} \mathrm{C}$ values ranging from -24 to $-22 \%$ and $\delta^{15} \mathrm{~N}$ values from 4 to $6 \%$ in the study area (Portail et al. 2018). Finally, values of $\delta^{34} \mathrm{~S}$ between $\sim 16 \%$ and $19 \%$ were considered representative of organic matter of photosynthetic origin, whereas values around and below $10 \%$ were considered of chemosynthetic origin (Reid et al. 2013). Because of the low number of samples $(n=1)$, the periphery site was excluded from all isotopic statistical analyses.

\section{Statistical analyses}

All indices and statistical tests were computed in $\mathrm{R} \mathrm{v}$. 3.5.3 (R Development Core Team 2019). Taxonomic indices were computed using the package vegan (Oksanen et al. 2019). Functional indices, null models, and Fig. 2 were computed using a modified version of the script provided by Teixidó et al. (2018) and the $d b F D$ function in the $F D$ package (Laliberté and Legendre 2010). Differences in mean taxonomic and functional metrics, as well as stable isotope ratios, were tested using ANOVAs or Kruskal-Wallis tests. Assumptions of normality and homogeneity of variances were tested using Shapiro-Wilk and Bartlett tests, respectively. Intersite post hoc comparisons were performed using Tukey honest significant difference tests or Dunn's test of multiple comparisons using rank-sum tests. $\beta$-diversity analyses and LCBD indices were calculated using the beta.div and beta.div.com functions in the adespatial package (Dray et al. 2019). db-RDAs were run with the capscale function in vegan after check for multivariate homogeneity of variances with the betadisper function coupled with permutations tests. MFAs and RV coefficients were computed using the FactoMineR package (Lê et al. 2008). Results

\section{Taxonomic and functional biodiversity metrics}

We identified 9,401 specimens of 78 species/morphotypes belonging to eight phyla (Appendix S4: Table S1), which exceeds the most extensive studies undertaken at the Lucky Strike vent field and the ET edifice to date (Van Dover and Trask 2000, Cuvelier et al. 2014, Sarrazin et al. 2015, Zeppilli et al. 2015, Plum et al. 2017, Baldrighi et al. 2018). This suggests that the colonizing experiment appears to be appropriate to address our goals, although species accumulation curves indicated that additional species are still to be found in all sites (Appendix S4: Fig. S1). Nine species ( $12 \%$ of the total species found) were found at all sites (Appendix S5: Fig. S2).

Statistical comparisons of diversity indexes are showed in Appendix S4: Table S2. Total species richness $\left(\mathrm{S}_{\text {Total }}\right)$ was lower in the periphery site (Table 2 and Fig. 2A). In fact, mean species richness (S) and abundance (N; Table 2) were lower in the periphery site compared to the active $(P=0.01$ and 0.002 , respectively $)$ and intermediate $(P=0.01$ and 0.04 , respectively) sites. The far site was also less abundant than the active site $(P=0.04)$. Rarefied species richness $\left(\mathrm{ES}_{(158)}\right)$, Simpson's index $(1-D)$ and evenness $\left(J^{\prime}\right)$ did not show significant differences, although they tend to increase from the active to the far sites (Table 2).

The 78 species/morphotypes represented 25 functional entities (FE) in total, of which 8 ( $32 \%$ of the total) were found in all sites (Appendix S2: Fig. S1). Total functional richness $\left(\mathrm{FRic}_{\mathrm{Total}}\right)$ and number of functional entities $\left(\mathrm{FE}_{\mathrm{Total}}\right)$ were higher in active and intermediate 
(A)

Active

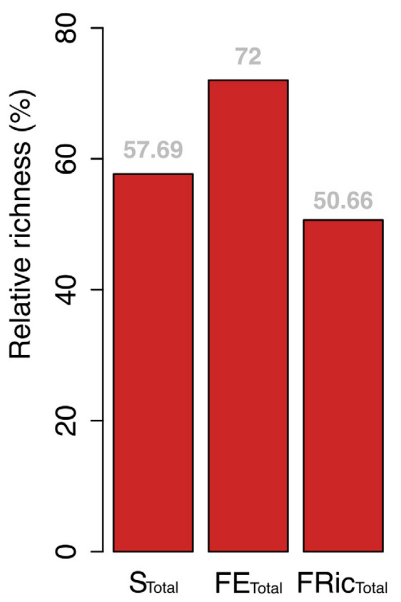

Intermediate

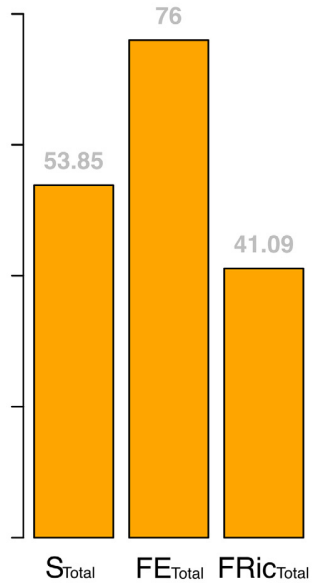

Periphery

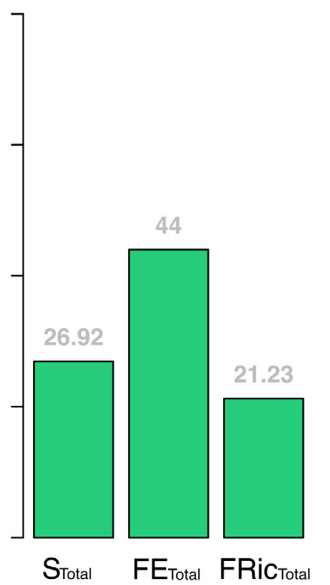

Far

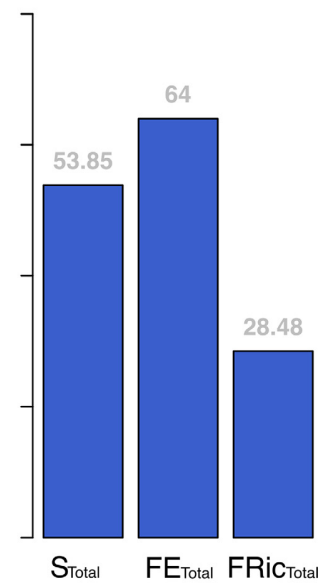

(B)

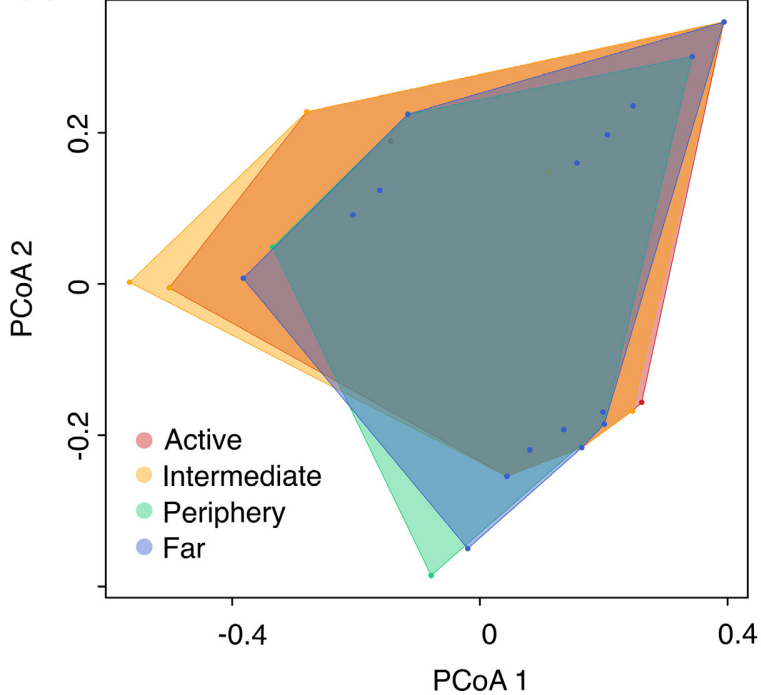

(C)

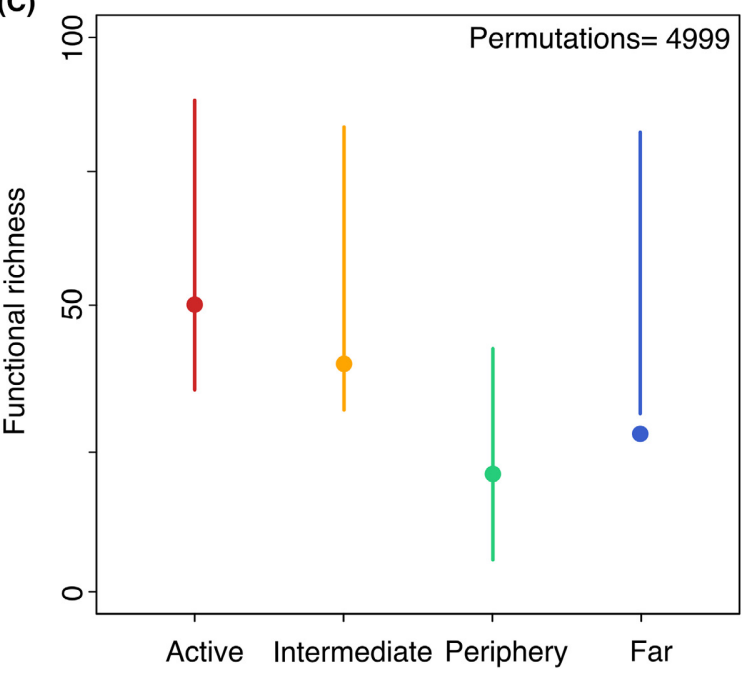

FIG. 2. (A) Percentage of total species $\left(\mathrm{S}_{\text {Total }}\right)$, functional entities $\left(\mathrm{FE}_{\text {Total }}\right)$, and richness $\left(\mathrm{FRic}_{\text {Total }}\right)$ per site. (B) Functional richness represented as the area in a twodimensional PCA space. Translucent colors are used to allow the visualization of functional space overlap and distribution of functional entities. (C) Null model of functional richness (FRic) among sites. Points are the observed values of FRic and bars represent the $95 \%$ confidence interval of expected values generated by simulating random species sorting from the total pool of functional entities $(n=25 \mathrm{FE})$, based on the observed number of species at each site.

sites (Fig. 2A,B, Table 2). Notably, despite FRic Total $_{\text {dif- }}$ ferences, functional spaces visualization revealed that all sites harbor unique FE (see imperfect overlap of functional spaces in Fig. 2B). Mean functional richness (FRic) was significantly higher in the active and intermediate sites than in the periphery $(P=0.0002$ and 0.001 , respectively) and far sites $(P=0.0006$ and 0.004 , respectively; Table 2; Appendix S4: Table S2). Mean functional entities (FE) were significantly higher in the active and intermediate sites than in the periphery $(P=0.0001$ and 0.00006 , respectively) and far sites $(P=0.001$ and 0.006 , respectively; Table 2; Appendix S4: Table S2). The number of rarefied functional entities $\left(\mathrm{EFE}_{(158)}\right)$ were higher in the intermediate site than in the periphery and far sites $(P=0.01$ and 0.03 , respectively; Table 2, Appendix S4: Table S2). Functional quadratic entropy (RaoQ) was higher in the active, intermediate and periphery sites than in the far site $(P=0.006,0.001$ and 0.03 , respectively), and higher in the intermediate site than in the periphery site $(P=0.03$; Table 2; Appendix S4: Table S2). Functional evenness (FEve) was lower in the active site compared to the periphery site $(P=0.025$; Table 2, Appendix S4: Table S2). Null models revealed that the observed FRic at the far site 
TABLE 2. Species and functional $\alpha$ - and $\beta$-diversity indices at the four study sites.

\begin{tabular}{llllll}
\hline \hline & Index & \multicolumn{1}{c}{ Active } & \multicolumn{1}{c}{ Intermediate } & \multicolumn{1}{c}{ Periphery } & \multicolumn{1}{c}{ Far } \\
\hline Species $\alpha$-diversity & $\mathrm{S}_{\text {Total }}$ & $\mathbf{4 5}$ & 42 & 21 & 42 \\
& $\mathrm{~S}$ & $\mathbf{3 1 . 6 7} \pm \mathbf{3 . 5 1}$ & $\mathbf{3 1} \pm \mathbf{3 . 6 1}$ & $11 \pm 0$ & $22.67 \pm 2.1$ \\
& $\mathrm{~N}$ & $\mathbf{1 1 , 6 0 7 . 2 4} \pm \mathbf{1 , 7 5 4 . 4 7}$ & $6,328.36 \pm 2702.65$ & $160.78 \pm 4.62$ & $573.04 \pm 265.27$ \\
& $\mathrm{ES}_{(158)}$ & $13.77 \pm 4.04$ & $15.52 \pm 1.11$ & $10.9 \pm 0.15$ & $\mathbf{1 5 . 9 8} \pm \mathbf{1 . 4 7}$ \\
& $1-\mathrm{D}$ & $0.66 \pm 0.23$ & $0.78 \pm 0.05$ & $0.71 \pm 0.03$ & $\mathbf{0 . 8 5} \pm \mathbf{0 . 0 7}$ \\
& $\mathrm{J}^{\prime}$ & $0.48 \pm 0.16$ & $0.58 \pm 0.05$ & $0.63 \pm 0.04$ & $\mathbf{0 . 7 3} \pm \mathbf{0 . 1 1}$ \\
& FRic $_{\text {Total }}$ & $\mathbf{5 0 . 6 6}$ & 41.09 & 21.23 & 28.48 \\
& FRic $_{\text {Functional } \alpha \text {-diversity }}$ & $\mathbf{3 7 . 1 2} \pm \mathbf{3 . 4 5}$ & $29.46 \pm 8.45$ & $2.17 \pm 1.47$ & $7.16 \pm 5.38$ \\
& FE & 18 & $\mathbf{1 9}$ & 11 & 16 \\
& FE & $15.33 \pm 0.58$ & $\mathbf{1 6} \pm \mathbf{1}$ & $7.67 \pm 0.58$ & $10 \pm 1.73$ \\
& EFE & & $\mathbf{1 0 . 4 9} \pm \mathbf{0 . 5 7}$ & $7.6 \pm 0.63$ & $8.02 \pm 0.65$ \\
& RaoQ & $0.65 \pm 1.36$ & $\mathbf{0 . 0 5 8} \pm \mathbf{0 . 0 0 7}$ & $0.023 \pm 0.005$ & $0.012 \pm 0.002$ \\
Species $\beta$-diversity & FEve & $0.21 \pm 0.05$ & $0.31 \pm 0.04$ & $\mathbf{0 . 3 7} \pm \mathbf{0 . 0 7}$ & $0.24 \pm 0.05$ \\
Functional $\beta$-diversity & LCsBD & $0.21(P=1)$ & $0.23(P=1)$ & $\mathbf{0 . 2 9}(P=0.04)$ & $0.28(P=0.15)$ \\
& LCfBD & $0.2(P=1)$ & $0.18(P=1)$ & $0.26(P=1)$ & $\mathbf{0 . 3 5}(P=0.03)$ \\
\hline
\end{tabular}

Notes: Higher values are highlighted in bold. $\mathrm{S}_{\text {Total }}=$ total species richness; $\mathrm{S}=$ mean species richness; $\mathrm{N}=$ mean abundance; $\mathrm{ES}_{(158)}=$ rarefied species richness to 158 individuals. $1-\mathrm{D}=$ Simpson's diversity index; $\mathrm{J}^{\prime}=$ Pielou's evenness index; FRic $\mathrm{Total}=$ total functional richness; FRic = mean functional richness; $\mathrm{FE}_{\mathrm{Total}}=$ total functional entities; $\mathrm{FE}=$ mean functional entities; $\mathrm{EFE}$ $(158)=$ rarefied functional entities to 158 individuals; RaoQ $=$ Rao's quadratic entropy index; FEve $=$ functional evenness; LC(s/f) $\mathrm{BD}=$ local contribution to (species/functional) $\beta$-diversity. $P=$ adjusted $P$ value. Highest values are highlighted in bold.

was lower than expected by chance, whereas FRic values at other sites fell within the expected values (Fig. 2C).

Total species $\beta$-diversity was higher than functional $\beta$ diversity $\left(\mathrm{sBD}_{\text {Total }}=0.34\right.$ and $\mathrm{fBD}_{\text {Total }}=0.23$, respectively) and both were mainly driven by turnover $(0.29$ and 0.16 , i.e., 84 and $69 \%$, respectively; Table 2). Nestedness nevertheless contributed roughly two times more to $\mathrm{fBD}_{\text {Total }}(0.07$, i.e., $31 \%)$ than to $\mathrm{sBD}_{\text {Total }}(0.05$, i.e., $16 \%$ ). The periphery and the far sites were the most dissimilar sites, the former contributing significantly more to $\mathrm{sBD}_{\text {Total }}$ than the other sites $(\mathrm{LCsBD}=0.29$, $P=0.04)$ and the latter to the $\mathrm{fBD}_{\text {Total }}(\mathrm{LCfBD}=0.35$, $P=0.03$ ) (Table 2). Pairwise comparisons of sites revealed low species and functional $\beta$-diversity dissimilarity (D) between the active and intermediate sites, which was mainly driven by turnover (Appendix S5: Table S1 and Appendix S5: Fig. S1). Unexpectedly, the periphery and far sites were as dissimilar, or in some cases more dissimilar to each other than they were to the active and the intermediate sites.

\section{Species and functional community structure}

Taxonomic groups and functional traits were unevenly distributed among sites (Fig. 3A,B) highlighting deep structural differences among sites. Copepods largely dominated the periphery and far sites, and nematodes dominated the active and intermediate sites. Largest sizes $(>15 \mathrm{~mm})$ were exclusively found in active and intermediate sites and predator abundance increased from the far to the active site. Supporting these observations, the dbRDA models with "sites" as a predictor variable explained 72.53 and $78.91 \%$ of the total variance in species and functional entities assemblage structures, respectively $(P=0.001$ in both models). These results were well illustrated in the MFA ordinations, which showed that different taxa and FEs characterized each site. Both species and functional entities were similarly structured in the four groups (Fig. 4A) and the RV coefficient (the relatedness of the two data sets derived from separate ordinations) between them was 0.93 $(P=0.01)$, further supporting this observation. The first axis of the global PCA (54.55\% of the global variance) separated active and intermediate colonizing blocks from the periphery and far-site blocks (Fig. 4A). The second axis (18.32\% of the global variance) further separated the periphery and far-site blocks, and the activesite blocks from the intermediate-site blocks. The species and functional entities contributing the most to the ordination of blocks in the first three axes of the global PCA are shown in Fig. 4B.

\section{Stable isotopes}

Mean $\delta^{13} \mathrm{C}$ values ranged from $-34.57 \%$ for the copepod Smacigastes micheli at the active site to $-17.39 \%$ for the polychaete Lepidonotopodium sp. at the far site (Appendix S3: Table S1). Mean $\delta^{15} \mathrm{~N}$ values ranged from $-7.05 \%$ for the polychaete Branchipolynoe seepensis at the active site to $9.89 \%$ for Lepidonotopodium sp. at the far site. Mean $\delta^{34} \mathrm{~S}$ values ranged from $2.65 \%$ in B. seepensis at the active site to $14.03 \%$ in Lepidonotopodium sp. at the far site. Active and intermediate sites did not show any differences in mean $\delta^{13} \mathrm{C}, \delta^{15} \mathrm{~N}$ and $\delta^{34} \mathrm{~S}$ values (Appendix S3: Fig. S1). Compared with active and intermediate sites, the far site had a significantly less negative mean $\delta^{13} \mathrm{C}(P=0.004$ and 0.03 , respectively), higher mean $\delta^{15} \mathrm{~N}$ (only compared to the intermediate site, $P=0.003)$, and higher mean $\delta^{34} \mathrm{~S}\left(P=23^{\mathrm{e}-05}\right.$ and $11^{\mathrm{e}-05}$, respectively) (Appendix S3: Fig. S1). Notably, 

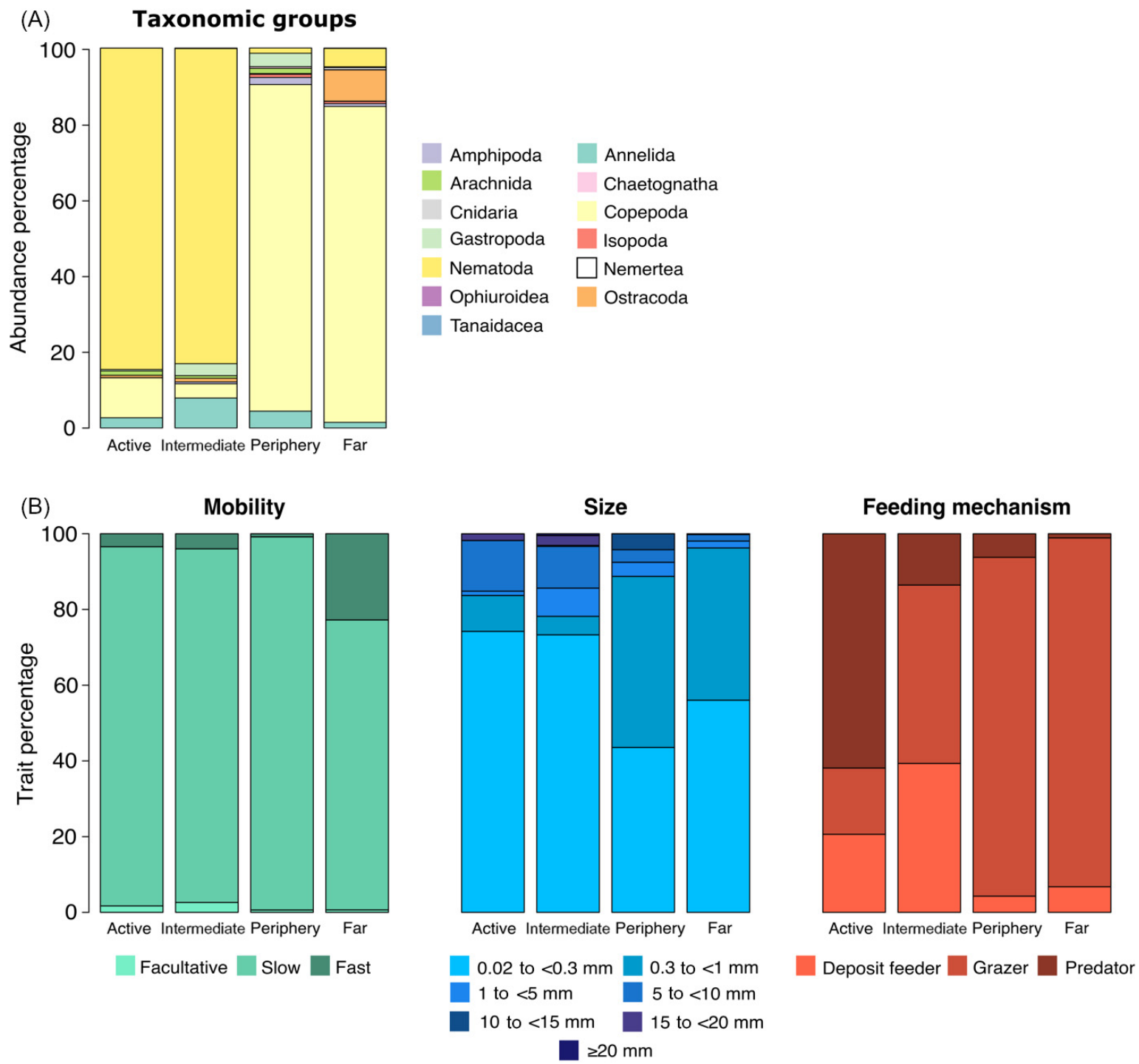

FIG. 3. Proportion of taxonomic groups (A) and trait categories (B) at the four study sites.

the gastropods Pseudorimula midatlantica and Lepetodrilus atlanticus, the annelids Ophryotrocha fabriae, Glycera tesselata, and Amphisamytha lutzi, and Nemertea sp., shared between active and intermediate sites, showed differences in $\delta^{13} \mathrm{C}, \delta^{15} \mathrm{~N}$, and $\delta^{34} \mathrm{~S}$ (Appendix S3: Table $\mathrm{S} 1$ and Fig. 1). This could be caused by intersite differences in isotopic composition of food items, feeding plasticity in those species, or both. The only available sample of the periphery site belonged to the amphipod Liljeborgidae sp. and its isotopic values were similar to those species analyzed at the far site (Appendix S3: Fig. S1).

\section{DisCUSSION}

It is well known that increases in hydrothermal activity decrease local species diversity in deep-sea vents
(Sarrazin et al. 2015, Gollner et al. 2015b) but its role on the functional diversity has remained unclear. Our results showed that despite the strong environmental stress, faunal assemblages colonizing substrata under high hydrothermal influence were functionally more diverse than assemblages in more stable surrounding areas without direct influence of vent emissions. The opposite trend has been observed in shallow-water hydrothermal vents $(<0.5-3-\mathrm{m}$ depth, Teixidó et al. 2018). Deep-sea vents are not only hotspots of primary production, but also of evolutionary novelties, thereby differing from their shallower counterparts, which have a very low degree of unique, well-adapted species (Tarasov et al. 2005). We suggest that concomitant productivity increases with stress can lead to the presence of not only well-adapted but functionally diverse assemblages in a 

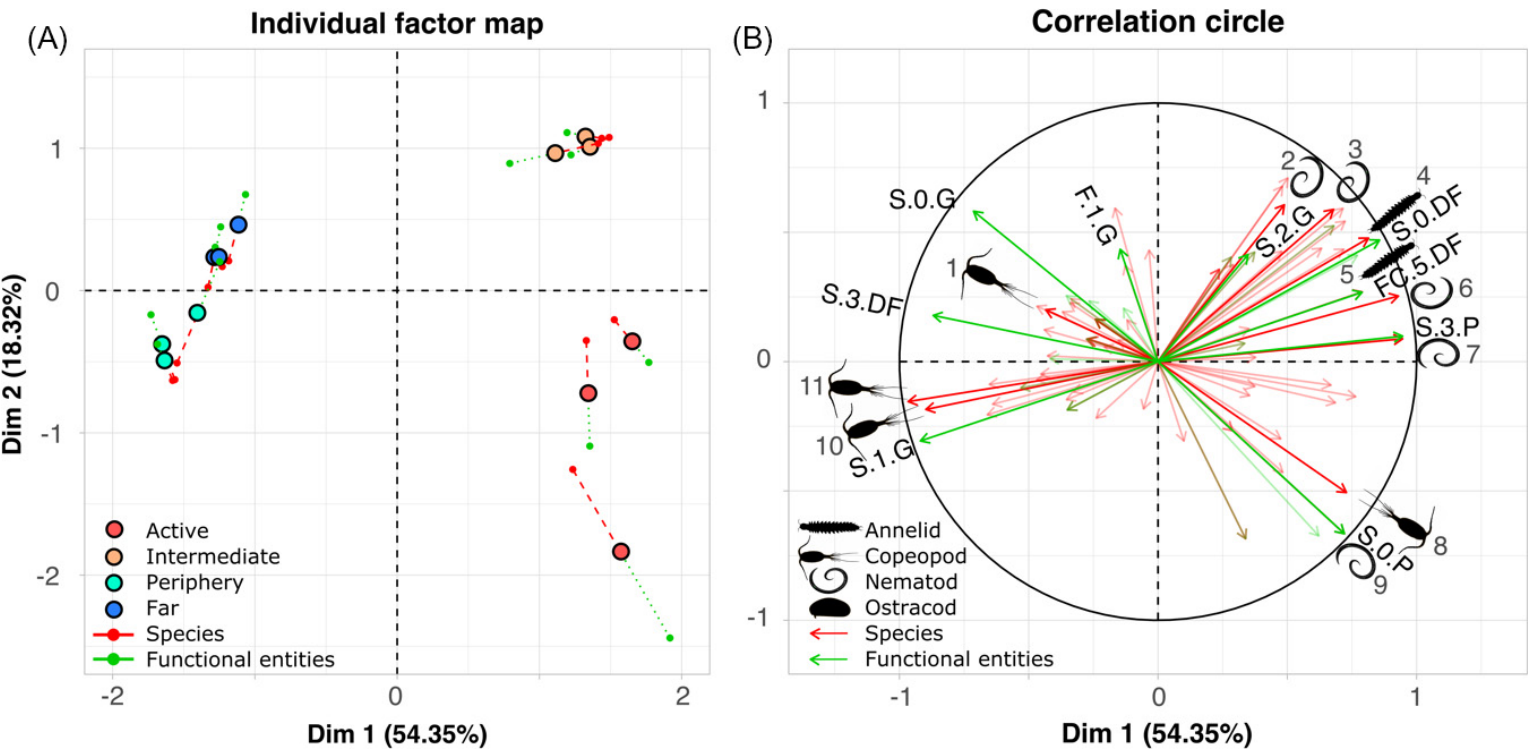

FIG. 4. Multiple factor analysis (MFA) of species and functional entities. (A) Individual factor map showing substrata positions for species and functional entities partial principal coordinate analysis (PCA), and the global PCA along the first and second axes. (B) Correlation circle highlighting the main taxa/functional entities contributing to the ordination of sites along the first and second axes. 1 = Ameiridae sp. 3, 2 = Chromadorita sp., $3=$ Microlaimus sp., $4=$ Ophryotrocha fabriae, $5=$ Amphisamytha lutzi, 6 = Cephalochaetosoma sp., $7=$ Oncholaimus dyvae, $8=$ Smacigastes micheli, $9=$ Paracanthonchus sp., $10=$ Ameiridae sp. 4 , $11=$ Ameiridae sp. 1, $12=$ Mesochra sp., $13=$ cf. Kelleriidae sp., $14=$ Ameiridae sp. $3,15=$ Thomontocypris excussa. Mobility: $\mathrm{S}=$ slow, $\mathrm{FC}=$ facultative, $\mathrm{F}=$ fast. Size: $0=0.02$ to $<0.3 \mathrm{~mm}, 1=0.3$ to $<1 \mathrm{~mm}, 2=1$ to $<5 \mathrm{~mm}, 3=5$ to $<10 \mathrm{~mm}, 4=10$ to $<15 \mathrm{~mm}, 5=15$ to $<20 \mathrm{~mm}, 6=>20 \mathrm{~mm}$. Feeding: $\mathrm{P}=$ predator, $\mathrm{DF}=$ deposit feeder, $\mathrm{G}=$ grazer. Copepod and annelid silhouettes were freely downloaded from PhyloPic under Public Domain Dedication 1.0 License.

context of poorly energy availability such as the deep sea. High functional diversity, that is, more distinct ecological functions among taxa, could lower interspecific competition, and facilitate species coexistence in high densities, in the spatially restricted diffusive flow vent areas, which strikingly contrasts with faunal patterns of the majority of the deep sea.

High functional diversity may reflect high ecosystem functioning and is usually associated with higher resilience of functions to perturbations (Cardinale et al. 2012). Moreover, null models revealed that functional richness was only lower than expected by chance at the far site ( $\sim 90 \mathrm{~m}$ away of hydrothermal fluid influence), suggesting strong trait convergence, which are patterns usually associated with environmental filtering (Chase 2010, Weiher et al. 2011, Teixidó et al. 2018). Under certain circumstances, competition may nonetheless also lead to species trait convergence (Mayfield and Levine 2010) and we did not undertake phylogenetic analyses to support trait patterns. Nevertheless, our results are concordant with recent studies in deep-sea oligotrophic systems that have shown that peracarid, nematode, and octocoral assemblages are also structured by environmental filtering (Quattrini et al. 2017, Ashford et al. 2018, Macheriotou et al. 2020). Assemblages structured by environmental filtering are typically considered more sensitive to disturbances than those structured by neutral processes and interspecific interactions (Didham et al. 2005, Ashford et al. 2018). Although more research is needed, low food availability could act as strong filter that locally limits colonization to species that are adapted to low-energetic regimes (Chase 2010). These results provide support to previous studies that have observed slower recovery on vent peripheral areas and have suggested that these assemblages may be especially vulnerable to environmental disturbances (Gollner et al. 2015a).

$\beta$-diversity analyses shed light on the observed differences in species and functional community structure. Species and FE assemblage dissimilarities were mainly driven by turnover indicating a substitution of species and FEs between sites. Local contributions of sites to $\beta$ diversity indices identified the periphery and far sites as contributing more than expected by chance to total species and functional $\beta$-diversity, respectively. In fact, the periphery and far sites were as dissimilar, or even more dissimilar to each other, than they were to the active and intermediate sites, highlighting the high species (Gollner et al. 2015a b) and functional heterogeneity of assemblages at deep-sea habitats away from hydrothermal influence. The lower species and functional dissimilarities between the active and intermediate sites highlight the role of stressful vent fluids as homogenizing forces (Luther et al. 2001, Sarrazin et al. 2015). However, some taxa found at sites with hydrothermal fluid influence 
were also commonly found at the periphery and far sites including the gastropod Lurifax vitreus, the polychaete Glycera tesselata, the amphipod Luckia striki, the ostracod Thomontocypris excussa, and the copepod Hepterina confusa, among others. This lack of specificity in some taxa may explain the relatively low total species $\left(\mathrm{sBD}_{\text {Total }}\right)$ and functional $\beta$-diversity ( $\left.\mathrm{fBD}_{\text {Total }}\right)$ observed $(0.34$ and 0.23 , respectively). Despite the prevalence of turnover, nestedness was about twice as important in functional $\beta$ diversity. This indicates the loss of some functions from the active and intermediate to the periphery and far sites.

Indeed, the largest-sized species ( $>15 \mathrm{~mm}$ ) were only found at active and intermediate sites, whereas very small sizes characterized the sites without hydrothermal influence. Large size may be advantageous in the vent environment, because it may help increase the animal's physiological tolerance to cope with a rapidly changing environment (see Vanreusel et al. 2010, Gollner et al. $2015 b$ and references therein). Size, however, also represents a direct link with energy (McGill et al. 2006), as does predation. Stable isotope analyses suggested a strong reliance on in situ chemosynthetic primary productivity of fauna from the active and intermediate sites, and the abundance of predator species strongly decreased from the active to the far sites. In agreement with food-web theory (Post 2002), these patterns strongly suggest that vent primary productivity sustains complex trophic assemblages with multiple trophic levels (Govenar 2012), and support the observed positive productivity-functional diversity relationship.

In the context of potential mining of vent systems (Van Dover et al. 2018, Van Dover 2019), our results strongly advocate precautionary measures. Rather than separate entities, areas with and without vent fluid influence should be considered as a continuum of biologically and trophic interconnected assemblages. Values of $\delta^{34} \mathrm{~S}$ around $16 \%$ and $19 \%$ are generally considered as representatives of organic matter of photosynthetic origin, whereas values around and below $10 \%$ are considered of chemosynthetic origin (Erickson et al. 2009, Reid et al. 2013). $\delta^{34} \mathrm{~S}$ values of species at far sites varied between $11 \%$ and $14 \%$. Thus, vent primary chemosynthetic production is exported at least as far as $\sim 90 \mathrm{~m}$ in the Lucky Strike vent field. This energy may be used by taxa exclusively found at these sites, establishing spatial subsidies that may extent the vent's "sphere of influence" (sensu Levin et al. 2016) far from areas under direct vent fluid influence (Reid et al. 2013, Bell et al. 2017, Ardyna et al. 2019, Le Bris et al. 2019). Much effort has been invested in raising awareness on the largely under-sampled and poorly studied inactive sulfide deposits, the main mining industry target (Van Dover 2019). Insights of this study, however, strongly suggest that historically overlooked heterogeneous adjacent vent areas as close as $<100 \mathrm{~m}$ harbor diverse assemblages with unique species and functional entities that may be affected by environmental changes such as those produced by anthropogenic activities (Van Dover et al. 2018).

\section{ACKNOWLEDGMENTS}

We thank the captains and crews of R/V Pourquoi pas?, the pilots of ROV Victor6000, and the technicians and engineers of the Laboratoire Environnement Profond (Ifremer) for their assistance at sea and in the lab. In particular, we would like to thank those who spent hours to help us handling our faunal samples at sea: M. Matabos, B. Husson, and E. Omnes. We thank Dr. P. Bonifacio, Dr. M. Shimabukuro, and Dr. L. Corbari for their assistance in fauna identifications. We thank Dr. A. Bates and Dr. A. Chapman for access to an early version of the sFDVent database. JMAL warmly thanks Dr. O. Gauthier, Dr. A. Bates, Dr. C. Rommevaux, Dr. P. Peres-Neto, and all members of the Laboratory of Community and Quantitative Ecology at Concordia University (Canada) for helpful advice, and fruitful discussions on early analyses and results of this manuscript. Dr. B. Fournier is acknowledged for his valuable help with the multiple factor analyses. JMAL warmly thanks R. Barbosa for help with drawing figures. We are very grateful for the helpful reviews by two anonymous referees. Authors acknowledge the project PIONEER funded by Ifremer and the Total Foundation. JMAL's Ph.D. scholarship was supported by the "Laboratoire d'Excellence" LabexMER (ANR-10LABX-19), co-funded by a grant from the French government as part of the "Investissements d'Avenir" capital expenditure program and by IFREMER. The research program was funded by an ANR research grant (ANR Lucky Scales ANR-14CE02-0008-02). The project is part of the EMSO-Azores regional node, and of the EMSO ERIC Research Infrastructure. The manuscript was professionally edited by Carolyn EngelGautier.

\section{LiTERATURE CITED}

Ardyna, M. et al. 2019. Hydrothermal vents trigger massive phytoplankton blooms in the Southern Ocean. Nature Communications 10:2451.

Ashford, O. S., A. J. Kenny, C. R. Froján, M. B. Bonsall, T. Horton, A. Brandt, G. J. Bird, S. Gerken, and A. D. Rogers. 2018. Phylogenetic and functional evidence suggests that deep-ocean ecosystems are highly sensitive to environmental change and direct human disturbance. Proceedings of the Royal Society B 285:20180923.

Baldrighi, E., D. Zeppilli, R. Crespin, P. Chauvaud, F. Pradillon, and J. Sarrazin. 2018. Colonization of synthetic sponges at the deep-sea Lucky Strike hydrothermal vent field (MidAtlantic Ridge): a first insight. Marine Biodiversity 48:89103.

Baselga, A. 2010. Partitioning the turnover and nestedness components of beta diversity. Global Ecology and Biogeography 19:134-143.

Bates, A. E., R. W. Lee, V. Tunnicliffe, and M. D. Lamare. 2010. Deep-sea hydrothermal vent animals seek cool fluids in a highly variable thermal environment. Nature Communications 1:1014.

Bell, J. B., W. D. Reid, D. A. Pearce, A. G. Glover, C. J. Sweeting, J. Newton, and C. Woulds. 2017. Hydrothermal activity lowers trophic diversity in Antarctic hydrothermal sediments. Biogeosciences 14:5705-5725.

Botta-Dukát, Z. 2005. Rao's quadratic entropy as a measure of functional diversity based on multiple traits. Journal of Vegetation Science 16:533-540.

Bris, N., M. Yücel, A. Das, S. M. Sievert, P. LokaBharathi, and P. R. Girguis. 2019. Hydrothermal energy transfer and 
organic carbon production at the deep seafloor. Frontiers in Marine Science 5:531.

Cardinale, B. J. et al. 2012. Biodiversity loss and its impact on humanity. Nature 486:59-67.

Chapman, A. S. et al. 2019. sFDvent: A global trait database for deep-sea hydrothermal-vent fauna. Global Ecology and Biogeography 28:1538-1551.

Chapman, A. S., V. Tunnicliffe, and A. E. Bates. 2018. Both rare and common species make unique contributions to functional diversity in an ecosystem unaffected by human activities. Diversity and Distributions 24:568-578.

Chase, J. M. 2010. Stochastic community assembly causes higher biodiversity in more productive environments. Science 328:1388-1391.

Chase, J. M., and M. A. Leibold. 2002. Spatial scale dictates the productivity-biodiversity relationship. Nature 416:427-430.

Cuvelier, D., J. Beesau, V. N. Ivanenko, D. Zeppilli, P.-M. Sarradin, and J. Sarrazin. 2014. First insights into macro- and meiofaunal colonisation patterns on paired wood/slate substrata at Atlantic deep-sea hydrothermal vents. Deep Sea Research Part I: Oceanographic Research Papers 87:70-81.

Desbruyères, D. et al. 2001. Variations in deep-sea hydrothermal vent communities on the Mid-Atlantic Ridge near the Azores plateau. Deep Sea Research Part I: Oceanographic Research Papers 48:1325-1346.

Didham, R. K., C. H. Watts, and D. A. Norton. 2005. Are systems with strong underlying abiotic regimes more likely to exhibit alternative stable states? Oikos 110:409-416.

Dray, S.et al. 2019. Adespatial: Multivariate Multiscale Spatial Analysis. R package version 0.3-4. https://CRAN.R-project.org/package $=$ adespatial

Erickson, K. L., S. A. Macko, and C. L. Dover. 2009. Evidence for a chemoautotrophically based food web at inactive hydrothermal vents (Manus Basin). Deep Sea Research Part II: Topical Studies in Oceanography 56:1577-1585.

Fabricius, K., G. De'ath, S. Noonan, and S. Uthicke. 2014. Ecological effects of ocean acidification and habitat complexity on reef-associated macroinvertebrate communities. Proceedings of the Royal Society B 281:20132479

Garrard, S. L., C. M. Gambi, B. M. Scipione, F. P. Patti, M. Lorenti, V. Zupo, D. M. Paterson, and C. M. Buia. 2014. Indirect effects may buffer negative responses of seagrass invertebrate communities to ocean acidification. Journal of Experimental Marine Biology and Ecology 461:31-38.

Gollner, S., B. Govenar, P. Arbizu, S. Mills, N. Bris, M. Weinbauer, T. M. Shank, and M. Bright. 2015a. Differences in recovery between deep-sea hydrothermal vent and vent-proximate communities after a volcanic eruption. Deep Sea Research Part I: Oceanographic Research Papers 106:167-182.

Gollner, S., B. Govenar, C. R. Fisher, and M. Bright. $2015 b$. Size matters at deep-sea hydrothermal vents: different diversity and habitat fidelity patterns of meio- and macrofauna. Marine Ecology Progress Series 520:57-66.

Gollner, S., B. Riemer, P. Arbizu, N. Bris, and M. Bright. 2010. Diversity of meiofauna from the $9^{\circ} 50^{\prime} \mathrm{N}$ East Pacific Rise across a gradient of hydrothermal fluid emissions. PLoS One 5:e12321.

Govenar, B.2010. Shaping vent and seep communities: habitat provision and modification by foundation species. Pages $403-$ 432 in S. Kiel, editor. The vent and seep biota, aspects from microbes to ecosystems. Topics in Geobiology, Vol. 33. Springer, Berlin, Germany.

Govenar, B. 2012. Energy transfer through food webs at hydrothermal vents: linking the lithosphere to the biosphere. Oceanography 25:246-255.

Govenar, B., L. N. Bris, S. Gollner, J. Glanville, A. Aperghis, S. Hourdez, and C. Fisher. 2005. Epifaunal community structure associated with Riftia pachyptila aggregations in chemically different hydrothermal vent habitats. Marine Ecology Progress Series 305:67-77.

Hall-Spencer, J. M., R. Rodolfo-Metalpa, S. Martin, E. Ransome, M. Fine, S. M. Turner, S. J. Rowley, D. Tedesco, and M.-C. Buia. 2008. Volcanic carbon dioxide vents show ecosystem effects of ocean acidification. Nature 454:96.

Johnson, K. S., Childress, J. J., Beehler, C. L., and Sakamoto, C. M. 1994. Biogeochemistry of hydrothermal vent mussel communities: the deep-sea analogue to the intertidal zone. Deep Sea Research Part I: Oceanographic Research Papers 41(7):993-1011.

Johnson, K. S., Childress, J. J., Hessler, R. R., SakamotoArnold, C. M., and Beehler, C. L. 1988. Chemical and biological interactions in the Rose Garden hydrothermal vent field, Galapagos spreading center. Deep Sea Research Part A. Oceanographic Research Papers 35(10-11):1723 - 1744.

Josse, J., J. Pagès, and F. Husson. 2008. Testing the significance of the RV coefficient. Computational Statistics \& Data Analysis 53:82-91.

Kroeker, K. J., F. Micheli, M. C. Gambi, and T. R. Martz. 2011. Divergent ecosystem responses within a benthic marine community to ocean acidification. Proceedings of the National Academy of Sciences of the United States of America 108:14515-14520.

Laliberté, E., and P. Legendre. 2010. A distance-based framework for measuring functional diversity from multiple traits. Ecology 91:299-305.

Lamanna, C. et al. 2014. Functional trait space and the latitudinal diversity gradient. Proceedings of the National Academy of Sciences of the United States of America 111:1374513750.

Lê, S., J. Josse, and F. Husson. 2008. FactoMineR: An R package for multivariate analysis. Journal of Statistical Software 25:1-18.

Lee, R., and J. Childress. 1996. Inorganic N assimilation and ammonium pools in a deep-sea mussel containing methanotrophic endosymbionts. Biological Bulletin 190:373-384.

Legendre, P. 2014. Interpreting the replacement and richness difference components of beta diversity. Global Ecology and Biogeography 23:1324-1334.

Legendre, P., and M. Cáceres. 2013. Beta diversity as the variance of community data: dissimilarity coefficients and partitioning. Ecology Letters 16:951-963.

Levin, L. A. et al. 2016. Hydrothermal vents and methane seeps: rethinking the sphere of influence. Frontiers in Marine Science 3:72.

Luther, G. W., III, T. F. Rozan, M. Taillefert, D. B. Nuzzio, C. Meo, T. M. Shank, R. A. Lutz, and C. S. Cary. 2001. Chemical speciation drives hydrothermal vent ecology. Nature 410:813.

Macheriotou, L., A. Rigaux, S. Derycke, and A. Vanreusel. 2020. Phylogenetic clustering and rarity imply risk of local species extinction in prospective deep-sea mining areas of the Clarion-Clipperton Fracture Zone. Proceedings of the Royal Society B 287:20192666

Mayfield, M. M., and J. M. Levine. 2010. Opposing effects of competitive exclusion on the phylogenetic structure of communities. Ecology Letters 13:1085-1093.

McClain, C. R., C. Nunnally, A. S. Chapman, and J. P. Barry. 2018. Energetic increases lead to niche packing in deep-sea wood falls. Biology Letters 14:20180294.

McClain, C. R., and M. A. Rex. 2015. Toward a conceptual understanding of $\beta$-diversity in the deep-sea benthos. Annual Review of Ecology, Evolution, and Systematics 46:623-642.

McClain, C. R., and T. A. Schlacher. 2015. On some hypotheses of diversity of animal life at great depths on the sea floor. Marine Ecology 36:849-872. 
McGill, B. J., B. J. Enquist, E. Weiher, and M. Westoby. 2006. Rebuilding community ecology from functional traits. Trends in Ecology \& Evolution 21:178-185.

Micheli, F., C. H. Peterson, L. S. Mullineaux, C. R. Fisher, S. W. Mills, G. Sancho, G. A. Johnson, and H. S. Lenihan. 2002. Predation structures communities at deep-sea hydrothermal vents. Ecological Monographs 72:365-382.

Mittelbach, G. G., C. F. Steiner, S. M. Scheiner, K. L. Gross, H. L. Reynolds, R. B. Waide, M. R. Willig, S. I. Dodson, and L. Gough. 2001. What is the observed relationship between species richness and productivity? Ecology 82:2381-2396.

Mouchet, M. A., S. Villéger, N. W. Mason, and D. Mouillot 2010. Functional diversity measures: an overview of their redundancy and their ability to discriminate community assembly rules. Functional Ecology 24:867-876.

Mouillot, D., N. Graham, S. Villéger, N. Mason, and D. R. Bellwood. 2013. A functional approach reveals community responses to disturbances. Trends in Ecology \& Evolution $28: 167-177$

Mullineaux, L. S., C. H. Peterson, F. Micheli, and S. W. Mills. 2003. Successional mechanism varies along a gradient in hydrothermal fluid flux at deep-sea vents. Ecological Monographs 73:523-542.

Oksanen, J., et al. 2019. vegan: community ecology package. $\mathrm{R}$ package version 2.5-4. https://CRAN.R-project.org/package= vegan

Plum, C., F. Pradillon, Y. Fujiwara, and J. Sarrazin. 2017. Copepod colonization of organic and inorganic substrata at a deep-sea hydrothermal vent site on the Mid-Atlantic Ridge. Deep Sea Research Part II: Topical Studies in Oceanography 137:335-348.

Portail, M., Brandily, C., Cathalot, C., Colaço, A., Gélinas, Y., Husson, B., Sarradin, P.-M., Sarrazin, J. 2018. Food-web complexity across hydrothermal vents on the Azores triple junction. Deep Sea Research Part I: Oceanographic Research Papers 131:101-120.

Post, D. M. 2002. The long and short of food-chain length Trends in Ecology \& Evolution 17:269-277.

Quattrini, A. M., C. E. Gómez, and E. E. Cordes. 2017. Environmental filtering and neutral processes shape octocoral community assembly in the deep sea. Oecologia 183:221-236.

R Development Core Team. 2019. R: A language and environment for statistical computing. R Foundation for Statistical Computing, Vienna, Austria. https://www.R-project.org/

Reid, W. D., C. J. Sweeting, B. D. Wigham, K. Zwirglmaier, J. A. Hawkes, R. A. McGill, K. Linse, and N. V. Polunin. 2013. Spatial differences in East Scotia ridge hydrothermal vent food webs: influences of chemistry, microbiology and predation on trophodynamics. PLoS One 8:e65553.

Robert, P., and Y. Escoufier. 1976. A unifying tool for linear multivariate statistical methods: the RV-coefficient. Journal of the Royal Statistical Society C 25:257-265.

Ruhl, H. A., J. A. Ellena, and K. L. Smith. 2008. Connections between climate, food limitation, and carbon cycling in abyssal sediment communities. Proceedings of the National Academy of Sciences of the United States of America 105:1700617011.

Ruhl, H. A., and K. L. Smith. 2004. Shifts in deep-sea community structure linked to climate and food supply. Science 305:513-515.

Sarradin, P.-M., M. Waeles, S. Bernagout, C. Gall, J. Sarrazin, and R. Riso. 2009. Speciation of dissolved copper within an active hydrothermal edifice on the Lucky Strike vent field $\left(\mathrm{MAR}, 37^{\circ} \mathrm{N}\right)$. Science of the Total Environment 407: 869-878.
Sarrazin, J., P. Legendre, F. de Busserolles, M.-C. Fabri, K. Guilini, V. N. Ivanenko, M. Morineaux, A. Vanreusel, and P.-M. Sarradin. 2015. Biodiversity patterns, environmental drivers and indicator species on a high-temperature hydrothermal edifice, Mid-Atlantic Ridge. Deep Sea Research Part II: Topical Studies in Oceanography 121:177-192.

Sarrazin, J., V. Robigou, K. Juniper, and J. Delaney. 1997. Biological and geological dynamics over four years on a hightemperature sulfide structure at the Juan de Fuca Ridge hydrothermal observatory. Marine Ecology Progress Series $13: 5-24$

Sen, A., S. Kim, A. J. Miller, K. J. Hovey, S. Hourdez, G. W. Luther, and C. R. Fisher. 2016. Peripheral communities of the Eastern Lau Spreading Center and Valu Fa Ridge: community composition, temporal change and comparison to near-vent communities. Marine Ecology 37:599-617.

Shank, T. M., D. J. Fornari, K. L. V. Damm, M. D. Lilley, R. M. Haymon, and R. A. Lutz. 1998. Temporal and spatial patterns of biological community development at nascent deepsea hydrothermal vents $\left(9^{\circ} 50^{\prime} \mathrm{N}\right.$, East Pacific Rise). Deep Sea Research Part II: Topical Studies in Oceanography 45:465515.

Sievert, S., and C. Vetriani. 2012. Chemoautotrophy at deep-sea vents: past, present, and future. Oceanography 25:218-233.

Snelgrove, P., and Smith, C. R. 2002. A riot of species in an environmental calm: the paradox of the species-rich deep-sea floor. Pages 311-342 in R. N. Gibson, M. Barnes, and R. J. A. Atkinson, editors. Oceanography and marine biology, An annual review 40. CRC Press, London.

Tarasov, V. G., A. V. Gebruk, A. N. Mironov, and L. I. Moskalev. 2005. Deep-sea and shallow-water hydrothermal vent communities: Two different phenomena? Chemical Geology 224:5-39.

Teixidó, N., M. Gambi, V. Parravacini, K. Kroeker, F. Micheli, S. Villéger, and E. Ballesteros. 2018. Functional biodiversity loss along natural $\mathrm{CO}_{2}$ gradients. Nature Communications 9:5149.

Van Dover, C. L. et al. 2018. Scientific rationale and international obligations for protection of active hydrothermal vent ecosystems from deep-sea mining. Marine Policy 90:20-28.

Van Dover, C. L. 2019. Inactive sulfide ecosystems in the deep sea: a review. Frontiers in Marine Science 6:461.

Van Dover, C. V., and J. Trask. 2000. Diversity at deep-sea hydrothermal vent and intertidal mussel beds. Marine Ecology Progress Series 195:169-178.

Vanreusel, A., A. Groote, S. Gollner, and M. Bright. 2010. Ecology and biogeography of free-living nematodes associated with chemosynthetic environments in the deep sea: a review. PLoS ONE 5:e12449.

Vizzini, S., B. Martínez-Crego, C. Andolina, A. Massa-Gallucci, S. D. Connell, and M. C. Gambi. 2017. Ocean acidification as a driver of community simplification via the collapse of higher-order and rise of lower-order consumers. Scientific Reports 7:4018.

Weiher, E., D. Freund, T. Bunton, A. Stefanski, T. Lee, and S. Bentivenga. 2011. Advances, challenges and a developing synthesis of ecological community assembly theory. Philosophical Transactions of the Royal Society B 366:24032413.

Zeppilli, D. et al. 2018. Characteristics of meiofauna in extreme marine ecosystems: a review. Marine Biodiversity 48:35-71.

Zeppilli, D., A. Vanreusel, F. Pradillon, S. Fuchs, P. Mandon, T. James, and J. Sarrazin. 2015. Rapid colonisation by nematodes on organic and inorganic substrata deployed at the deep-sea Lucky Strike hydrothermal vent field (Mid-Atlantic Ridge). Marine Biodiversity 45:489-504. 


\section{SUPPORTING INFORMATION}

Additional supporting information may be found in the online version of this article at http://onlinelibrary.wiley.com/doi/ 10.1002/ecy.3144/suppinfo

\section{Data Availability Statement}

Associated data are available from the Dryad Digital Repository: https://doi.org/10.5061/dryad.r4xgxd292 